\title{
DOSSIÊ O SIGNIFICADO DA TRADUÇÃO E A TRADUÇÃO DO SIGNIFICADO
}




\section{O SIGNIFICADO DA TRADUÇÃO E A TRADUÇÃO DO SIGNIFICADO*}

Kanavillil Rajagopalan**

\section{A}

ntes de qualquer outra coisa, cabe a mim, como coordenador, destrinchar e desvendar o próprio título que sugeri para a mesa. Quando pensei nesse título e convidei os dois colegas para compor a mesa, havia um forte sentimento de que a tradução e o significado estão atrelados entre si. Afinal, todas as grandes divergências no campo de reflexões teóricas sobre a tradução se configuram como divergências entre formas diferentes de pensar a semântica da tradução. Mas o motivo principal para a escolha do título para a mesa foi uma pergunta - ou melhor, uma provocação - dirigida a mim logo após a minha apresentação num congresso internacional sobre tradução que ocorreu na Inglaterra em 1997: "Exactly what does translation mean to you?". Foi uma pergunta que veio da platéia logo após a minha apresentação. Como ela foi feita oralmente, revelou-se um tanto ambígua e, por conseguinte difícil de ser respondida de forma sucinta. Para quem trabalha com questões de semântica $e$ pragmática, a caça a ambigüidades e vaguidades que permeiam os enunciados em língua natural acaba se transformando em uma obsessão vocacional. A ambigüidade no caso do enunciado em discussão tinha a ver com aquilo que seria

* Este texto é uma versão escrita da minha contribuição para uma mesa-redonda sob o mesmo título que coordenei durante $4^{\circ}$ Encontro do Celsul, Curitiba, dia 16 de novembro de 2000. O texto está fiel à sua versão oral no espírito, não nos detalhes. Sou grato ao CNPq pela concessão da bolsa de produtividade em pesquisa - processo $n$. $306151 / 88-0$.

** Universidade Estadual de Campinas. 
RAJAGOPALAN, K. O significado da tradução e a tradução...

sinalizado, caso a pergunta tivesse sido feita de forma escrita, pela presença ou não de aspas sobre a palavra tradução - ou outros recursos igualmente eficientes como o uso de caracteres em itálico ou a prática de sublinhar a palavra para assinalar que se trata de uma menção (e não do uso propriamente dito), ou modo formal (em oposição ao modo material), ou ainda para frisar que a pergunta em si está sendo formulada numa metalinguagem em relação à qual a palavra em destaque seria pertencente a uma linguagem-objeto.

Trocando (ou traduzindo?) em miúdos, o dilema despertado pela pergunta "Exatamente o que significa tradução para você?" estava relacionado à seguinte dúvida: De qual das seguintes sentenças interrogativas, ela se assemelha: (a) "Aquelas manchas escuras na pele significam o quê?" (b) "O que significa Übersetzung em alemão?" Note-se que o emprego da palavra em alemão pede que ela seja escrita com letras itálicas. As aspas sobre a palavra tradução na seguinte pergunta tem a mesma função: "O que significa 'tradução' para você?". Pois, em ambos os casos o destaque serve para alertar o leitor para o fato de que se trata de um nível de análise diferente do da própria pergunta.

Qualquer pessoa que teve iniciação no campo da semântica sabe que apenas perguntas do tipo (b) são da alçada dessa disciplina. As do tipo (a) fogem à competência do semanticista. Só um dermatologista pode confirmar se há ou não a necessidade de se preocupar com o aparecimento repentino de manchas na pele, ao passo que um dicionário bilíngüe resolve, via de regra, uma pergunta do tipo (b).

Voltando, pois, à pergunta "Exactly what does translation mean to you?", o dilema que ela provocou teve a ver com o fato de que o contexto dentro do qual tal pergunta foi feita favorecia que ela fosse compreendida como pertencente tanto ao tipo (a) como ao tipo (b). Como é sabido, o campo de pesquisas em torno da questão de tradução tem sido palco de controvérsias e polêmicas acirradas nos últimos tempos. Já se foi o tempo em que havia um quase consenso tanto entre os tradutores com os tradutólogos de que traduzir uma obra de língua $x$ para uma outra língua $y$ consistia basicamente em transportar o significado contido na obra original para a língua de chegada. Até pouco tempo atrás, os autores de livros introdutórios sobre tradução afirmavam com total confiança que traduzir significa transportar significados. Por exemplo, Pinchuk (1977: p. 35) declara que "[a] tradução é a transferência de significados" e observa que "[o]s procedimentos da tradução são instrumentos técnicos utilizados a fím de transferir o significado de um texto em uma determinada língua para um texto em uma outra língua" (Pinchuk, 1977, p. 188).

Já Popovic (1970) não só aceita como ponto pacífico a questão de transferência, mas entende que, nesse processo, é de se esperar que haja algum tipo 
de perda: "O objetivo da tradução é transferir certos valores intelectuais e estéticos de uma língua para outra. A transferência não é feita diretamente e nem tampouco está isenta de dificuldades. As perdas que ocorrem no processo são de tal magnitude que chegam às vezes a abalar a nossa fé na própria possibilidade de traduzir uma obra de arte." (Popovic, 1970, p. 78). Enquanto Pinchuk e Popovic divergem entre si quanto à natureza do objeto que cada um entende que a tradução transporta ou transfere de uma língua para uma outra, ambos estão de pleno acordo sobre a natureza do processo tradutório em si.

Aqui entre nós, há quem defenda que a transferência, quando se trata de "valores estéticos" (presumivelmente, em oposição aos "intelectuais") é possível, porém acarreta um esforço no sentido de ir além do significado. Assim, para Mário Laranjeira (1989), o que deve ser transportado pelo tradutor de poesia é algo que ele chama de a "significância", atributo este que, em sua ótica, distingue a poesia dos demais gêneros lingüísticos e literários. Cabe ressaltar que o próprio tradutólogo brasileiro recusa o termo "teoria" para caracterizar a sua proposta, preferindo descreve-la como uma "poética (não propriamente uma teoria) da tradução" (ênfase acrescida) (Laranjeira, 1989, p. 9). Eis uma síntese da sua proposta:

No multifacetado universo da atividade tradutora, propusemonos isolar e apontar a especificidade da tradução da poesia, desse texto singular que é o poema. Dentro do quadro geral da tradutologia, distinguimos três blocos conforme a natureza dos textos que constituem o objeto da tradução: o texto veicular, o literário não poético, e o poético, cuja manifestação mais representativa é o poema. Sobre esse último é que concentraremos as nossas considerações. Cada um desses blocos tem um modo diferente de significar, devendo, portanto, ser tratado diferentemente pelo tradutor. Assim a tradução do poema será função da sua maneira específica de produzir sentidos, a que chamamos "a significância". A tradução do poema deve, pois, ultrapassar o patamar do "sentido" com referencialidade exterior ao texto que enfatiza o significado, para atingir o nível da geração interna de sentidos mediante o trabalho do sujeito na cadeia dos significantes. Traduzir o poema sem perder a poeticidade será, então, traduzir a sua "significância" (Laranjeira, 1989, p. 9-10). 
Ou seja, resumindo ainda mais, a poesia se distingue pelo seu atributo de "significância"- logo, só traduz um poema na plenitude dos seus sentidos quem consegue transportar ao leitor não só o significado do texto que está sendo traduzido, mas também a sua "significância". Popovic e Laranjeira divergem quanto à possibilịdade de transportar (seja "valores intelectuais e estéticos", seja a "significância") sem perda ao longo do processo tradutório, mas estão em pleno acordo sobre a necessidade do transporte em si; no caso do segundo, a idéia de transporte funciona como um pressuposto básico - e, portanto nem sequer entendido como digno ser explicitado - de toda sua elucubração teórica (ou, como ele mesmo insiste em dizer, "poética").

Os três teóricos (apesar da relutância de um deles em aceitar o título), com todas as divergências e formas diferentes de encarar o ofício, estão discutindo o significado da "tradução". Ou seja, se qualquer um dos três estivesse participando desta mesa, provavelmente teria interpretado o título da mesa como "O significado da tradução e a tradução do significado", isto é, acrescentando, por conta própria, os itálicos (ou aspas) etc. para destacar a primeira ocorrência da palavra "tradução" e, dessa forma, proporcionando-lhe um tratamento metalingüístico. Ademais, qualquer um dos três estudiosos diria que, uma vez efetuado o "conserto" no título, poder-se-ia dizer que a segunda parte do título, isto é, "a tradução do significado" é o significado da "tradução". Isto é, a "tradução" - anote bem, a palavra portuguesa, assim com a palavra alemã Übersetzung e a palavra francesa traduction, significa o transporte do significado. Dito de outra forma, só faz sentido falar em "tradução do significado" se se entender a (palavra) "tradução" como tendo um significado preciso e estável a saber, a idéia do transporte.

Acredito que os três teóricos da tradução acima referidos, ao nos oferecem uma análise do título desta mesa mais ou menos na linha sugerida no parágrafo anterior, estarão seguindo à risca aquilo que é possível dentro dos limites epistemológicos tradicionalmente aceitos pela lingüistica, ou talvez pela metafísica do mundo ocidental. É por esse motivo que Barbara Johnson, em seu ensaio magistral "Taking translation philosophically", nos assegura que a tradução "sempre foi a tradução do significado" (Johnson, 1989, p. 24). Ao afirmar isso, Johnson está ecoando a posição mantida por Derrida (passim, especialmente, 1981) de que a própria noção do significado transcendental que serve de conceito fundador de toda a metafísica ocidental tem sua origem na crença na traduzibilidade perfeita de tal significado.

Ou seja, uma interpretação do título proposto para a mesa nos termos sugeridos no parágrafo anterior, estaria em perfeito acordo com aquilo que po- 
deríamos chamar de “a lingüística da tradução". No fundo, nada há de se estranhar nessa afirmação, pois, conforme já vimos, não compete ao lingüista responder o que significam as manchas escuras que de repente aparecem no pescoço de alguém ou na pacata praia em algum recanto paradisíaco deste país tropical. Sem as aspas sobre as palavras "manchas escuras" a pergunta precisa de outros especialistas - dermatologistas, técnicos da Petrobrás etc.

No que se segue, pretendo tecer algumas considerações acerca da(s) possibilidade(s) de se discutir o título proposto para esta mesa, sem acrescentar as aspas. Afinal, de forma diferente à pergunta feita durante o congresso no exterior, a que deu origem ao título, o convite que estendi aos meus colegas da mesa continha o título em sua forma escrita, com a sugestão de que ele fosse interpretado de maneira que cada um bem entendesse ou achasse útil ou conveniente para seus propósitos teóricos. Até onde me lembro, havia até mesmo uma sugestão de que o próprio título fosse submetido a um exame crítico.

Vamos então à pergunta: "O que significa tradução?". Vou direto a uma possível resposta e suas variantes, para então proceder a justificá-la. Tradução significa poder. Significa que existe uma distribuição desigual do poder "lectal" entre as línguas/dialetos envolvidos. Significa uma certa distensão, um certo rompimento nas relações entre as partes envolvidas. Evidentemente, há diferenças muito sutis entre as três. Mas, uma coisa todas elas têm em comum. Recorrendo-se à terminologia peirceana, pode-se dizer que a primeira "Tradução significa poder" sinaliza para uma relação indexical entre os termos "tradução" e "poder" e não para uma relação simbólica como em " 'Tradução' significa transporte". Em outras palavras, a relação entre tradução e poder seria semelhante àquela entre fumaça e fogo. Onde há tradução, com certeza, pode-se detectar a presença do poder. No caso da segunda e da terceira, o conceito de poder é substituído pela distribuição desigual do poder "lectal" e um certo estado de convivência difícil.

O que significa dizer que a tradução acena em direção à presença do poder etc.? Antes de tentar responder essa pergunta, permita-me esclarecer que o uso da palavra "significa" nada tem a ver com os usos até agora esmiuçados. Prova disso é que eu poderia ter feito a mesma pergunta, dizendo coisas do tipo: "Quais os desdobramentos, as conseqüências, de dizer etc." ou "O que implica dizer etc.".

Significa que a tradução é uma atividade, uma empreitada, imbuída de conotações políticas e ideológicas. Com isso, não se quer dizer apenas que a indústria de tradução toma suas decisões sob óticas ideológicas e políticas. Dependendo dos interesses ideológicos em jogo, as editoras privilegiam certas 
RAJAGOPALAN, K. O significado da tradução e a traduçāo...

obras estrangeiras para serem traduzidas e, dessa forma, divulgadas entre o público alvo. Isso ocorre até mesmo no mundo acadêmico em que, a despeito de todo o discurso a favor da livre circulação de idéias, certas vozes são abafadas e certas bocas amordaçadas com frequência surpreendente. $O$ poder cuja presença a tradução denuncia é algo quase invisível e, por isso, muitas vezes simplesmente ignorado. Como diz Niranjana (1992, p. 2): "A tradução como uma prática molda e, ao mesmo tempo, se processa no interior das relações de poder assimétricas que operam sob o colonialismo. O que está em jogo aqui é a representação do colonizado, que precisa ser produzida de tal maneira que justifique a dominação colonial."

Alguns dados apresentados por Lawrence Venutti (1996) são estarrecedores. Em prol da sua afirmação de que "A língua inglesa permanece a língua mais traduzida do mundo, porém também uma das línguas para a qual menos se traduz" (Venutti, 1996, p. 327), o autor cita os seguintes dados: a participação de obras traduzidas no total de livros publicados pelas editoras norte-americanas e britânicas não passa de um pífio $2 \%$, ao passo que a indústria editorial japonesa registra $6 \%$, a francesa $10 \%$, a húngara $14 \%$, a alemã $15 \%$, e a italiana $25 \%$. Para Venutti, tal assimetria significa que os dois países anglofônicos gozam de hegemonia absoluta em relação aos países estrangeiros, hegemonia essa que não é só de ordem política ou econômica, mas cultural também. Venutti observa que

[...] o risco representado pela posição marginal da tradução constitui narcisismo e complacência culturais, uma despreocupação com o estrangeiro, que só pode empobrecer a cultura anglo-americana e promover valores e políticas baseados em desigualdades e exploração. (Venutti, 1996)

A observação de Venutti procede. Isolamento, quer adotado como tática de auto-defesa, quer imposto por outros países em retaliação a atitudes consideradas inaceitáveis, já arruinou diversos países ao longo da história. Os danos políticos e econômicos são graves, mas mais graves ainda são os prejuízos na esfera cultural. A médio ou longo prazo, essa atitude de se auto-enclausurar numa torre de marfim cultural deve redundar num gradativo esgotamento e eventual definhamento da própria cultura desses povos que hoje desprezam as demais culturas. 
Há, no entanto, um outro lado da moeda que Venutti parece não estar interessado em examinar. Pois, Venutti vê o problema só do lado de quem está no mando no que diz respeito ao fluxo das informações via tradução. Cabe a nós olharmos para o fenômeno do ponto de vista de quem está na situação periférica. Para os periféricos, o grande desafio do momento não é o de não ter acesso a outras culturas, mas, sim, o de ter que lidar com o excesso da cultura alheia que lhes é imposta de forma agressiva e unilateral. A consequiência imediata da atitude arrogante e discriminatória por parte daqueles que detêm o poder sobre a circulação livre de informações é justamente a marginalização dos interesses daqueles que são excluídos do poder decisório. E esses interesses dizem respeito ao direito de se representar e de serem representados. Os países periféricos e suas culturas não são representados de forma adequada ou são representados, com frequiência, de maneira caricatural ou tendenciosa. No fim das contas, trata-se do direito de falar e ser ouvido.

A tendência crescente do monopólio que se verifica no mundo dos telejornais transmitidos em escala global via satélite é prova contundente da ameaça que a concentração do poder de informação em poucas mãos representa para o mundo inteiro. É sabido que, as grandes emissoras que hoje dominam o setor exercem uma espécie de poder de censura ao selecionarem (como não podia ser de outra forma) as notícias que vão ao ar e, dentre elas, as que vão receber destaque. O que é mais assustador é que os magnatas da mídia estão se tornando um poder à parte (aliás sempre foram detentores de um poder paralelo ao do próprio governo e, por esse motivo, chamados de "o quarto estado"), ameaçando a independência dos pequenos países, cujos governos legítimos encontram cada vez mais dificuldades em veicular as suas próprias versões sobre os acontecimentos para a opinião pública mundial. Sobre esse assunto, Phillipson (1992, p. 61) tem as seguintes palavras a dizer:

Um traço central da estrutura imperialista é que a interação [entre as partes] é assimétrica. Isso pode ser claramente depreendido do imperialismo da mídia, uma das formas do imperialismo cultural que já foi extensamente investigado e que tem afinidades com o imperialismo lingüístico nos sistemas educacionais. [...] Pouquíssimos produtos, idéias, e influências saem da periferia em direção ao centro. Por exemplo, muitos países sub-desenvolvidos e a Escandinávia são dependentes da [agência] Reuter's para as notícias do exterior. O fluxo no caminho oposto é mínimo. Pesquisa feita na Finlândia mostra que a Reuter's, uma agên- 
RAJAGOPALAN, K. O significado da tradução e a traduçāo...

cia privada com base em Londres, tem servido de "a janela para o mundo" para aquele país. (os itálicos são do próprio autor citado).

Pennycook (1994, p. 213) analisa a situação na Malásia da seguinte forma:

O inglês desempenha um papel importante na mídia. Embora a circulação dos jornais em língua inglesa em 1983 fosse um terço do total, com 813.000 exemplares, comparada aos 1.521 .000 exemplares para jornais em chinês e 1.163 .000 em malai (e $189.000 \mathrm{em}$ tamil), os jornais ingleses têm um papel importante em virtude da qualidade do público-alvo, que tem maior formação escolar, é em grande parte urbano e recebe salários mais elevados.

O que tudo isso mostra é que o fenômeno chamado o "imperialismo lingüístico" está presente em nosso meio não só pela presença esmagadora das línguas hegemônicas - notadamente o inglês - em nossas vidas, mas pela presença velada mesmo naquelas atividades cotidianas nossas onde menos suspeitaríamos a influência, ou melhor, a ingerência, dos valores alheios. Em outras palavras, a indústria da tradução é, sem sombra de dúvida, cúmplice nessa marcha desenfreada dos países ricos em direção ao total domínio cultural do resto do mundo.

Voltando ao nosso tema central, a tradução significa poder - isto é um desequilíbrio na distribuição do mesmo. Lembre-se que "o significado da tradução" não tem nada a ver, portanto, com "o significado da tradução". Cabe responder, então uma última pergunta antes de encerrar o raciocínio desenvolvido neste trabalho. Se, conforme já vimos, a tradução do significado depende (ou melhor, é uma conseqüência direta) do significado da "tradução" (ou da tradução, como bem quiser), que efeito tem para o restante do título da mesa a possibilidade, a que acabamos de examinar, de se referir ao significado da tradução (sem aspas, itálicos etc.)?

Parece-me que falar da tradução (sem aspas, itálicos etc.) nos obriga a substituir "a tradução do significado" por "a tradução do 'significado" ". Ou seja, a nossa escolha se restringe às duas opções seguintes: 
1) O significado da "tradução" e a tradução do significado.

2) O significado da tradução e a tradução do "significado".

Aviso importante: as aspas sobre a segunda ocorrência da palavra significado em (2) são de natureza completamente diferente das aspas sobre a primeira ocorrência da palavra tradução em (1). As aspas sobre significado em (2) não podem ser substituídas pelas convenções de pôr as letras em itálico ou sublinhá-las. A convenção que rege o segundo caso é diferente e não deve ser confundida com a que rege a primeira. Trata-se daquilo que podemos chamar de "aspas de alerta" - elas servem para alertar o leitor para o fato de que o emprego da palavra ("significado", no caso) deve ser entendida como não inteiramente adequado ou que o próprio autor tem ressalvas a fazer sobre o seu emprego no caso.

Uma das implicações da afirmação de que a tradução significa poder é de que não se pode mais referir ao significado como se esse conceito fosse unívoco. A pergunta que devemos fazer sempre é: "Significado para quem?". Para os detentores do poder, tem-se um determinado significado; para aqueles que estão fora, o significado é outro - ou melhor, pode vir a ser outro. A diferença entre uma atitude derrotista ou conformista e uma atitude de enfrentamento, de resistência está precisamente na forma como o destinatário se posiciona em relação aos significados que lhe são entregues.

Para explicitar ainda melhor a possibilidade de múltiplos significados, talvez devêssemos modificar o (2) em (2')

2') Os significados da tradução e a tradução do "significado".

\section{RESUMO}

Argumenta-se, nesse trabalho, que o próprio título escolhido para a mesa-redonda (da qual o presente texto serviu de palavras de abertura) é ambíguo. Falar do significado da "tradução' é uma coisa. O significado da tradução (sem aspas) é outra. A tradução (sem aspas) significa poder, isto é, a distribuição desigual de poder entre as partes envolvidas.

Palavras-chaves: Significado, tradução, poder, pós-colonialismo. 


\section{ABSTRACT}

It is argued in this paper that the very title chosen for this session (of which the present text constituted the opening words) is ambiguous. To talk about the meaning of "translation" is one thing. The meaning of translation (without the inverted commas) is a totally different thing. Translation means power, that is to say, the uneven distribution of power between the parties involved.

Key-words: Meaning, translation, power, post-colonialism.

\section{REFERÊNCIAS}

DERRIDA, J. (1981). Positions. Chicago: Chicago University Press.

JOHNSON, B. (1989). Taking translation philosophically. In: Difference in translation. Baltimore: Johns Hopkins University Press. p. 142-148.

LARANJEIRA, M. Do sentido à significancia: em busca de uma poética da tradução. São Paulo, 1989. (Doutorado) - Faculdade de Filosofia, Letras e Ciências Humanas da Universidade de São Paulo. No prelo.

NIRANJANA, T. (1992). Siting translation: History, poststructuralism, and the colonial context. Berkeley, CA: University of California Press.

PENNYCOOK, A. (1994). The cultural politics of english as an international language. London: Longman.

PHILLIPSON, R. (1992). Linguistic imperialism. Oxford: Oxford University Press.

PINCHUK, I. (1977). Scientific and technical translation. Londres: Andre Deutch.

POPOVIC, A. (1970). The concept of "shift of expression" in translation analysis. In: HOLMES, J. S. (Org.). (1970). The nature of translation: essays in the theory and practice of literary translation. Haia: Mouton. p. 78-87.

VENUTTI, L. (1996). Translation and the pedagogy of literature. College English, v. 58, n. 3, p. 327-344. 